\title{
O PROCESSO LUDOTERAPÊUTICO NA PERSPECTIVA FENOMENOLÓGICO-EXISTENCIAL DAS CRIANÇAS EM ATENDIMENTO CLÍNICO
}

The play therapy in the phenomenological-existential perspective of children in clinical care

\section{El terapia de juego en la perspectiva fenomenológica-existencial de los niños en la atención clínica}

Resumo: Este estudo surgiu diante da necessidade de ampliar a compreensão acerca da psicoterapia infantil de bases humanistas e fenomenológico-existencial. Objetivou-se compreender essa modalidade de intervenção clínica a partir da perspectiva infantil, conhecendo os significados atribuídos ao processo terapêutico, ao psicólogo e à participação delas próprias nos atendimentos clínicos. O estudo é qualitativo, de base fenomenológica, e tem como participantes seis crianças de idades entre seis e dez anos, em atendimento ludoterápico há no mínimo seis meses, indicadas pelas próprias psicoterapeutas. A análise dos dados foi pautada na variante do método fenomenológico proposta por Amadeo Giorgi. Os resultados revelam um desconhecimento prévio da atividade do psicólogo por parte de crianças encaminhadas à psicoterapia; que os significados associados aos motivos para um encaminhamento ao psicólogo evidenciam o conflito "ser um problema versus ter um problema"; que as características do processo terapêutico, como as especificidades da relação cliente-terapeuta e a noção de liberdade, são compreendidas pelas crianças; e que elas demonstram notável prazer no processo terapêutico, embora sinalizem algumas dificuldades. Por fim, conclui-se que os significados que as crianças conferem à psicoterapia mostram-se coerentes com o proposto na literatura sobre o processo psicoterapêutico infantil na perspectiva Humanista e Fenomenológico Existencial.

Palavras-chave: ludoterapia; infância; Fenomenologia.

\begin{abstract}
This study emerges from the necessity of enlarge the comprehension about this modality of clinical practice. Is aimed the comprehension of Ludotherapy through children's perspective, knowing the ascribed meanings toward the therapeutic process, the psychologist, and the participation of the children in the treatment. Is a qualitative study, of phenomenological basis, and participants, six children in the age group between six and ten years old, in ludotherapic treatment for at least six months, indicated by the therapists. Data analysis was guided by a variant of the phenomenological method proposed by Amadeo Giorgi. Results showeda previous unknowledge about psychologist's activity by children referred to Ludotherapy; the meanings associated to the motives of a referral to the psychologist highlight the conflict "be a problem versus have a problem"; the characteristics of the therapeutic process, like the specificities of the relation client-therapist and the notion of freedom, are comprehended by children; they show, yet, notable pleasure in the therapeutic process. Finally, is concluded that the meanings children ascribe to Ludotherapy are coherent to those proposed in the literature on infant's psychotherapeutic process under the Humanist and Phenomenological perspectives.
\end{abstract}

Key-words: play therapy; childhood; phenomenology.

Resumen: Este estudio surgió de la necesidad de aumentar la comprensión de la psicoterapia humanista infantil y la base existencial-fenomenológica. Este estudio tuvo como objetivo comprender este tipo de intervención clínica desde la perspectiva del niño, conociendo los significados atribuidos al proceso terapéutico, el psicólogo y la participación de los mismos en la atención clínica. El estudio es base cualitativa, fenomenológica, y sus participantes seis niños de edades comprendidas entre los seis y los diez años e nel cuidado ludoterápico durante al menos seis meses seña lados por los propios psicoterapeutas. El análisis de datos se basa en la variante del método fenomenológico propuesto por Amadeo Giorgi. Los resultados ponen de manifiesto la falta de actividad previo psicólogo por los niños que se refiere a la psicoterapia; los significados atribuidos a las razones de una derivación a un psicólogo muestran el conflicto "se a un problema en lugar de tener un problema”; que las características del proceso terapéutico como los específicos de la relación cliente-terapeuta y la noción de libertad, son entendidos por los niños; y que muestran una notable placeren el proceso terapéutico, aunque se mantienen algunas dificultades. Por último, se concluye que los significados que los niños dan al espectáculo de la psicoterapia es coherente con la propuesta en la literatura sobre el proceso psicoterapéutico en los niños Existencial Humanista y la perspectiva fenomenológica.

Palabras clave: terapia de juego; la infancia; La fenomenología.

\section{Introdução}

Este artigo apresenta os significados que as crianças em atendimento clínico humanista ou fenomenológico-existencial atribuem ao próprio processo psicoterapêutico. Entende-se como significado a estrutura essencial ou invariante do fenômeno, desvelada através da descrição da experiência em determinada situação (Andrade e Holanda, 2010). Já como Ludoterapia considera-se o processo psicoterapêutico em que a escuta e a fala, mediadas e vividas pelo brincar, possibilitam à criança lidar com o seu sofrimento.

Dentre as principais finalidades do atendi- 
mento clínico infantil têm-se: a) construir com a criança uma experiência de permanência consigo, mobilizando o autocuidado (Feijoo, 2011); b) possibilitar às crianças o desenvolvimento de formas de enfrentamento da situação angustiante, reconhecendo o problema sem, no entanto, permitir que os conflitos as afastem daquilo que são (Protásio, 1998); c) estimular potencialidades que, até então, estavam subjugadas a uma realidade vitimizadora (Vitola, Minella e Silveira, 2009); d) propiciar oportunidades para que seja resgatado o curso satisfatório do desenvolvimento infantil (Aguiar, 2014); e) promover e legitimar um espaço de protagonismo infantil (Forteski et al., 2014).As possibilidades elencadas não são mutuamente excludentes e podem ser mais ou menos valorizadas dependendo da especificidade da linha teórica do psicoterapeuta.

De forma geral, o objetivo da pesquisa foi compreender os significados atribuídos àspsicoterapias de bases humanistas ou fenomenológico-existencial, a partir da narrativa de crianças em acompanhamento psicoterápico. Especificando os caminhos de investigação, deu-se por objetivos: 1) introduzir a perspectiva da criança na compreensão do processo psicoterapêutico; 2) compreender os significados que a criança atribui à figura do psicoterapeuta e; 3) compreender como a criança percebe sua participação no processo psicoterapêutico.

Estudos com essa temática são importantes porque pesquisas com crianças estão sujeitas às dificuldades na elaboração e consolidação de instrumen- tos e métodos que, coerentes com a cultura infantil, validem a relevância de seus resultados (Aveline, Strauss \& Stiles, 2007; Ceitlin, Manfro, Jung \& Cordioli, 2008; Cruz, 2008; Müller \& Carvalho, 2009; Sousa, 2006). Além disso, esse tipo de discussão abre espaço para uma nova categoria de articulação, aquela cujos sujeitos das intervenções clínicas podem abertamente expressar suas percepções sobre a experiência vivida e, por conseguinte, contribuir à análise do escopo de teorias que embasam a atuação do psicoterapeuta. Este desafio é especialmente importante à psicologia clínica, pois a mesma necessita aproximar a prática clínica à produção do conhecimento (Avelineet al., 2007; Ceitlinet al., 2008; Feijó \& Oliveira, 2016; Melo \& Caldas, 2013; Sousa, 2006).

\section{Método e materiais}

Trata-se de uma pesquisa qualitativa fundamentada no método fenomenológico, a partir do modelo desenvolvido por Giorgi $(1985,1997)$. O material foi submetido ao Comitê de Ética em Pesquisa (CEP) da Universidade Federal do Rio Grande do Norte e sua aprovação está documentada no protocolo $\mathrm{n}^{\circ} 020 / 10$, parecer $\mathrm{n}^{\circ} 082 / 2010$.

Participaram da investigação seis crianças em processo psicoterápico de base humanista ou fenomenológico-existencial com, no mínimo, seis meses de duração. Não houve restrições quanto à queixa inicial para o atendimento. Os nomes que identificam as crianças são fictícios e foram escolhidos por elas.

\section{Tabela 1 Participantes}

Quadro de participantes da pesquisa

\begin{tabular}{|c|c|c|c|c|}
\hline NOME & IDADE & SERVIÇO & TEMPO & QUEIXA \\
\hline Jack & 6 & Privado & 1 ano & Agressividade \\
\hline Lê & 6 & Privado & 2 anos & Falta de limites \\
\hline Ingrid & 7 & Público & 7 meses & Atraso no desenvolvimento \\
\hline Daniel & 8 & Púbico & 1 ano & Anorexia infantil \\
\hline $\begin{array}{l}\text { Super- } \\
\text { Homem }\end{array}$ & 9 & Público & 2 anos & $\begin{array}{l}\text { Luto pela morte materna, tendo } \\
\text { presenciado o assassinato da mãe pelo } \\
\text { padrasto }\end{array}$ \\
\hline Barbie & 10 & Público & 1 ano & $\begin{array}{l}\text { Em acolhimento institucional, com } \\
\text { crises de "birra" e comportamento } \\
\text { sexual precoce }\end{array}$ \\
\hline
\end{tabular}

Como instrumentos foram utilizados:

a) Nos encontros individuais orientados por questões norteadoras foram utilizados como mediadores da expressão infantil uma "Caixa Lúdica", contendo papel ofício A4, lápis grafite, borracha, coleção de lápis de cor, coleção de lápis hidrocor, massa de modelar, tesoura, gliter e cola; e uma Mala de Figuras, contendo gibis infantis em quadrinhose tesoura;

b) História Incompleta, que consistiu na contação da história de Gil, inicialmente narrada pela pesquisadora e, depois, completada pela criança: A casa de Gil tinha um despertador muito, muito, muito alto; sempre que ele tocava todo mundo acordava. Era um TRIM TRIMTRIM que fazia a família inteira ficar de pé. Mas naquele dia o reloginho não precisou tocar, pois antes mesmo de o barulho começar, Gil já estava de olhos bem abertos. Na verdade, ele nem tinha dormido direito, porque no jantar a mãe tinha dito que de manhã eles iriam ao psicólogo. Devagarzinho o menino afastou o lençol, sentou-se na rede [Gil achava que a rede era a me- 
lhor cama do mundo] e ficou pensando em como ia ser o dia. Pensou que não tinha terminado o dever da aula de matemática, que o cachorro tinha levado a meia suja, que estava com saudade de comer ovo e que ia conhecer o psicólogo. Então teve uma ideia.

c) "Recado", um pedido de elaboração de um recado para crianças que ainda não conhecem o psicólogo.

Todos os áudios dos encontros foram registrados por um gravador de voz.

A estrutura dos procedimentos e a seleção das perguntas norteadoras foram definidas após a realização de um estudo piloto. Feito isto, estruturaram-se três encontros com cada criança, realizados ou na clínica onde trabalha o psicólogo ou na própria sala de psicoterapia (antes ou depois da sessão semanal do cliente/paciente). No primeiro encontro foi realizado momento mediado pela caixa lúdica, cujo objetivo foi estabelecer $o$ rapport com a criança e introduzir a temática da psicoterapia. No segundo, foi estabelecido o diálogo com questões voltadas à experiência da psicoterapia e foi utilizada a Mala de Figuras, pedindo à criança que recortasse cenas das revistas em quadrinhos que mostrassem sentimentos, pensamentos e/ou comportamentos relacionados à atividade do psicólogo. No terceiro encontro foi utilizada a História Incompleta e a elaboração do Recado, além de realizado o encerramento dos encontros.

A análise dos dados teve por base a variante do método fenomenológico proposta por Giorgi (1985,1997), que se estrutura em quatro fases: 1) transcrição literal das falas e uma leitura inicial geral; 2) leitura repetida do material de fala e discriminação das unidades de significado que constituem o fenômeno; 3) conversão das unidades de significado para a linguagem científica e aprofundamento teórico; 4) e por fim, síntese das unidades de significado em um texto coeso que apresente aos leitores a compreensão da experiência estudada.

\section{Resultados}

A partir do objetivo proposto foram discriminadas cinco unidades de significados: a) o desconhecimento da profissão; b) quem vai ao psicólogo e quais os motivos para um encaminhamento; c) o que faz o psicólogo; d) as características da Ludoterapia; e) a apreciação da Ludoterapia.

\section{O desconhecimento da profissão}

A familiaridade das crianças com o psicólogo parece ter sido construída a partir da inserção delas em seu atual processo terapêutico. Anterior ao fato, o que se percebe é ou um desconhecimento em relação à profissão ou uma dificuldade em expressar o que se sabe sobre ela, havendo até contradições.

$$
\begin{aligned}
& \text { P: Já conhecia algum psicólogo? } \\
& \text { J: Não. } \\
& \text { P: Você conhece outra pessoa que vai para o } \\
& \text { psicólogo? } \\
& \text { J: Nããããâa...”. }
\end{aligned}
$$

Daniel também afirma desconhecer o profissional. Entretanto, o diferencial é que, neste caso, a falta de conhecimento potencializa o medo. Fala de Daniel:
P: Você já tinha conhecido algum psicólogo antes de vir para cá?
D: Não.

P: $O$ que você imaginou quando ela disse que você ia conhecer um psicólogo?

D: Fiquei com medo (...) que eu fiz uma cirurgia e fiquei com muito medo!

$P$ : Você fez cirurgia?

D: Da boca. Coloca uma [inaudível] e enfia uma mangueira aqui dentro.

P: Então quando sua mãe disse que você ia para o psicólogo, você ficou com medo.

D: Fiquei.

P: O que você achava que o psicólogo ia fazer?

D: Eu não sei.(...) Cirurgia.

Considerando que as crianças formam uma parcela significativa dos clientes da psicoterapia, tal desconhecimento ou falta de clareza nas informações nos faz questionar o porquê de tal realidade e quais as consequências disso para o processo ludoterapêutico. Ora, se o sucesso do processo terapêutico está condicionado à implicação do cliente (Sousa, 2006),como haverá implicação se não se sabe qual é o trabalho do profissional? Pode-se indagar se o desconhecimento das crianças em relação ao trabalho do psicólogo teria relação com a história da psicologia, alicerçada em trabalho clínico de consultório, e com a dificuldade dos pais em abordar, de forma explícita, os motivos que justificam a necessidade de buscar a ajuda deste profissional.

Segundo a história do trabalho clínico, a acessibilidade ao profissional era possível apenas às crianças que demandavam serviços de consultório/avaliativo. Com a inserção do psicólogo em outros espaços, tais como escolas (não apenas na "sala de psicologia", mas em outras atividades), hospitais, instituições jurídicas ou assistenciais, entre outros, essa realidade vem se transformando. Agora, algumas vezes a criança vai até ao psicólogo e, em outras, ele vai até ela. Entretanto, se mesmo com esta colaboração do cenário profissional ainda há crianças que desconhecem a profissão, constatamos que ainda temos um longo percurso para alcançar maior inserção social, sendo preciso que o psicólogo continue a investir nesta aproximação. Da mesma forma, também é preciso que o profissional divulgue seu trabalho, afirmando a existência da psicologia e explicitando a diferença entre sua função e a função dos outros profissionais (como as "tias", enfermeiras, professoras).

Outra possibilidade é a de que os pais, ainda baseados na ideologia do mito da criança feliz, percebam a necessidade de procurar ajuda como uma evidência de que fracassaram na função parental. Isso, associado a expectativas sociais cada vez mais elevadas em torno do desempenho dos filhos, poderia estar contribuindo para o silenciamento (ou falando apenas o "mínimo necessário") em relação 
à intervenção psicoterapêutica. Assumir a necessidade da psicoterapia seria declarar que a família difere das famílias ditas "normais e felizes". Neste sentido, a literatura aponta os sentimentos contraditórios que pais/responsáveis têm quando comparecem à primeira entrevista, tais como sensação de impotência, defesas pessoais, temores, entre outros (Feijoo, 2004; Fernandes, 2010; Phillipi, 2010). Assim, falsear as explicações dadas à criança, seja alterando a identidade do profissional ("Ele é o seu amigo" ou "Ele é um médico") ou, simplesmente, não a explicando, torna-se uma boa alternativa para disfarçar essas angústias, afastando, consequentemente, a psicoterapia (e o psicólogo) do cotidiano dos filhos

\section{Quem vai ao psicólogo e quais os motivos para um encaminhamento?}

Embora relatem ter poucas informações sobre a psicoterapia antes da primeira hora terapêutica, as crianças demonstram ter um conhecimento mais estruturado sobre os usuários do serviço e sobre os motivos que justificam um encaminhamento para a Ludoterapia.

P: E o que é que precisa acontecer para a pessoa vir para o psicólogo?

D: Tá doente!

P: Tá doente. Então quem não está doente não vem?

D: Não vem. E quem tem deficiência. (...) Eu não sou doente, mas tenho deficiência. (...) Tenho medo. Sou muito medroso.

\section{P: Todo mundo pode vir para cá?}

J: Não. (...) Só quem bate, quem chuta. Dá murro no colega... Deixe eu ver, chuta... É... Coloca o pé pra ele cair... É isso.

Na atividade da Mala de Figuras, Ingrid justificou a escolha das imagens:

[figura 1], "Essa mulher está com vergonha"; [figura 2] "Essa daqui porque ele endoidou... É... E... Porque ele tá maluco." ;[figura 3] " I: Porque ele ficou triste e (...) porque ele viu besteira. Aí o povo "peguem o pato, peguem o pato!" E ele ficou com medo. Esse aqui tá perdido.

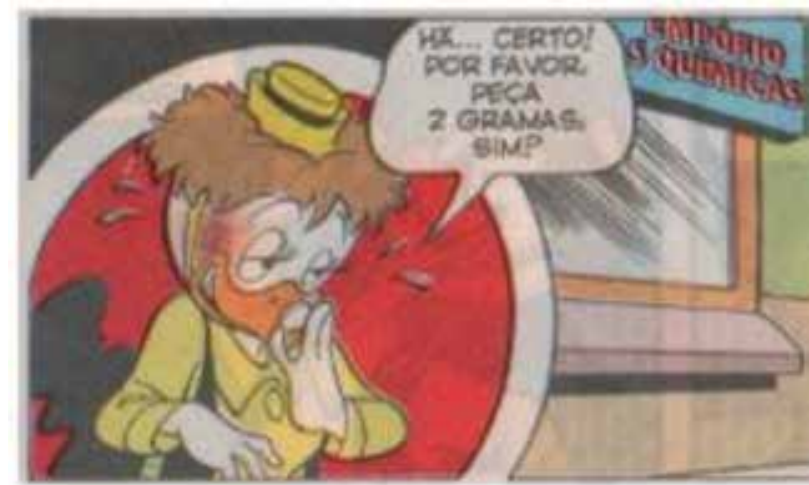

Figura 1. Mulher com vergonha.

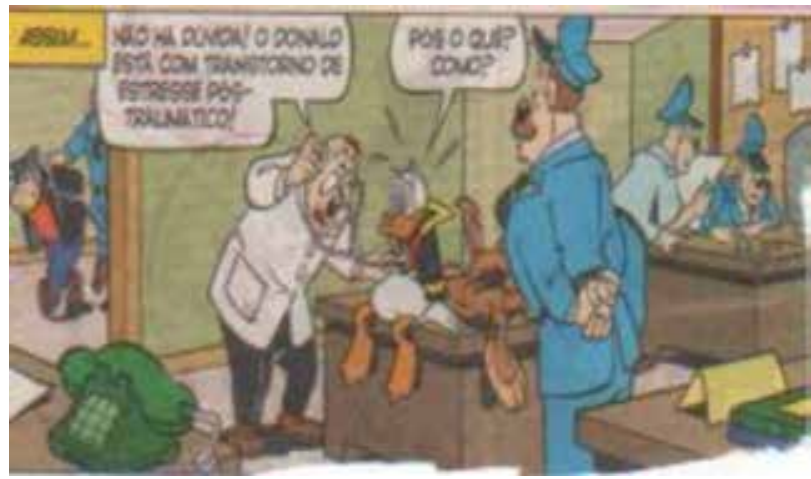

Figura 2. Homem doido.

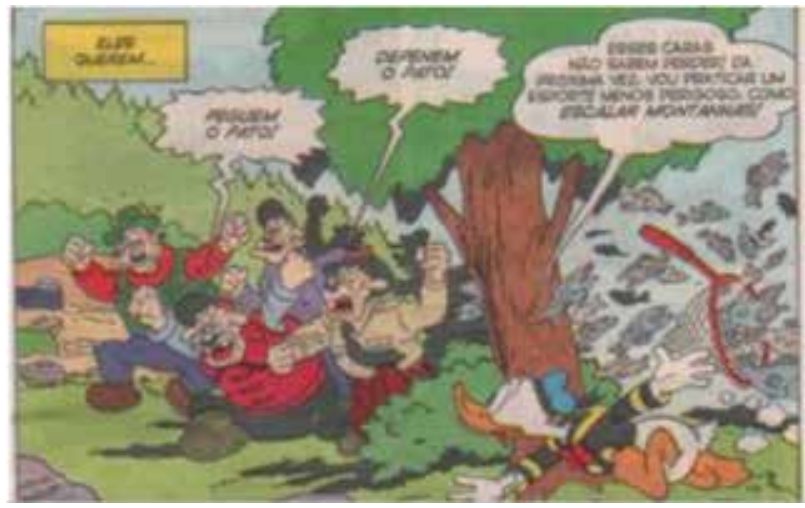

Figura 3. Homem perdido.

Em suas narrativas os participantes expressam que a criança vai ao psicólogo porque precisa, seja por um comportamento - bater, brigar - ou devido a sentimentos como medo, vergonha, tristeza; significados como "estar perdido" ou louco são também associados à terapia. Para Daniel, ser medroso é uma deficiência. Assim, o que temos é a representação da "criança problemática", cujos sentimentos e comportamentos são significados como desvios e anormalidade, e não como sofrimento. Esse cenário potencializa e mantém a polarização da mitológica criança feliz versus a criança-problema que está fora dos parâmetros.

O ponto nodal dessa discussão é que a manutenção dessa polaridade traz consigo uma nova categorização para o sofrimento infantil: de "criança que tem um problema", passamos a ter a "criança que é um problema”. Como consequência têm-se, dentre outras, o desencadeamento de um processo cíclico que gera culpabilização tanto dos pais, quanto da própria criança e, consequentemente, converte o problema em si (e todas as variáveis que o fomentam) em uma existência problemática.

Percebe-se também que essa visão do psicólogo como o profissional que trata o problema e não o sofrimento é um legado do modelo de psicologia clínica infantil que se ocupava em corrigir os comportamentos desviantes das crianças e orientar os pais quanto à sua normatização. É preciso lembrar que o surgimento dos serviços especializados na infância aconteceu diante da necessidade de higienizar as diferenças (Abrão, 2009; Costa, 1989; Gondra, 2000; Guarido, 2007). Neste sentido, a Ludoterapia também aparece representando um privilégio de classe. 


\begin{abstract}
P: E todo mundo pode ir para o psicólogo?
L: Nãããão.(...) Porque quem é ladrão, quem vive no mundo... Tem gente que não tem dinheiro.

P: E quem é que pode ir?

L: Pessoas que têm dinheiro, pessoas que não é maaau.

\section{P: Todo mundo pode vir para o psicólogo? \\ B: Quase todo mundo...(...) aquelas pessoas que tem vontade de vir pra um psicólogo...que tem um sonho de ir pro psicólogo... \\ $P:$ E tem alguém que não pode? \\ $B:$ Aquelas pessoas que vivem na rua, que vi- vem pedindo...}

Quando as crianças delimitam que somente pessoas boas ou aquelas que têm dinheiro, ou ainda as que ostentam certo tipo de privilégios, podem recorrer à psicoterapia, elas reafirmam a discussão sobre a elitização da psicologia clínica. Os questionamentos que embasam as críticas ao modelo clínico tradicional versam exatamente sobre aquilo que foi apresentado pelas crianças: pessoas pobres, sem dinheiro, que vivem em sistemas periféricos ao sistema urbano, não podem demandar os serviços dos profissionais psicólogos. Tal concepção, apontada e criticada, inicialmente, a partir dos debates da Psicologia Social, tem sido alvo de reflexões, também, dos próprios teóricos da Psicologia Clínica, que ratificaram a necessidade de assumir um compromisso com a população em geral. Em consequência disso, hoje muito se discute sobre a inserção do referencial social na atuação do psicólogo clínico e, ainda, sobre a chamada ampliação do modelo de atendimento (Amorim et al., 2015; Barreto et al., 2013; Parise et al., 2011; Paulon, 2004).

Por fim, na construção de sua História Incompleta, Super-Homem complementa:

P: Aí Ramon [personagem da história] perguntou: mas por que você vai para o psicólogo?

$\mathrm{SH}$ : Porque eu vou brincar.

$P$ : E eu posso ir lá brincar também?

SH: Não, é só pra alguém que perdeu alguém da família e precisa ser tratado.

$P$ : E se eu não tiver perdido alguém da família e quiser ir para o psicólogo, eu posso?

SH: Não.

Nesses relatos a criança associa a ida ao psicólogo a eventos que causam sofrimento psíquico, reafirmando a psicoterapia como o espaço para apropriação de seus sentimentos e necessidades (Aguiar, 2014; Feijoo, 2011; Vitolla, Minella\& Silveira, 2009) frente à situação dolorosa. A consciência de que o psicólogo é um profissional que disponibiliza para a criança um ambiente terapêutico propício ao crescimento e à construção de novos significados aos eventos favorece a experiência da Ludoterapia, bem como desmistifica a ideia de que a psicoterapia estaria relacionada à anormalidade e não ao sofrimento.

\section{O que faz o psicólogo? Qual o objetivo da} Ludoterapia?

Quando se remeteram ao trabalho do psicólogo, as crianças fizeram referências aos recursos utilizados por ele, aos objetivos na utilização de tais recursos e, consequentemente, à função deste profissional.

O desenho e a pintura são considerados pela literatura como registros que revelam a percepção da criança sobre determinado assunto. $\mathrm{O}$ uso de tais recursos é estimulado porque possibilita à criança a liberdade de expressar exatamente o que ela quiser. Seja o desenho da família ou de um universo desconhecido, ou ainda de um menino ou menina quaisquer, há liberdade para escolher o que registrar e como registrar (Aguiar, 2014; Cognet, 2013). Em outras palavras, são fantasias grafadas. O uso terapêutico se dá na medida em que, semelhante ao brinquedo e à leitura, permitem que a criança expresse o que sente e organize seus pensamentos. Além disso, os materiais podem ser resgatados nas sessões posteriores como recursos para comparar a percepção do fato no instante em que foi feito e no agora, decorrido o tempo. Sobre isso as crianças falam:

B: O que o psicólogo faz? A gente conversa, brinca, pinta com eles se a gente quiser.

P: O que você faz lá dentro da sala?

D: Brinco, brinco, brinco, brinco, brinco, brinco e deseeenho.

Sobre a brincadeira, percebe-se que ela aparece como a principal atividade da psicoterapia, assemelhando-se a uma marca registrada. Entendido como a linguagem "natural" da criança, o brincar media a expressão dos sentimentos e possibilita a organização da percepção dos fatos (Aguiar, 2014; Axline, 1972; Oaklander, 1980). Ele foi escolhido como mediador do processo terapêutico infantil porque, quando comparado ao uso exclusivo da fala, apresentou-se mais adequado à faixa etária e, consequentemente, às necessidades das crianças (Dorfman, 1951/1987). A brincadeira aparece, também, representada por sua função psicoterapêutica.

SH: Brinca com a gente pra mexer na cabeça. Pra tirar tudo... Tudo que a criança brinca de ruim. Tudo que aconteceu no passado, que às vezes a família da criança morreu, aí tenta distrair a criança com os brinquedos.[pausa] Todas as psicólogas são de ajuda, tenta distrair a mente da criança.(...)Na sala pode brincar de qualquer coisa.

P: E por que é que o psicólogo deixa a criança brincar de qualquer coisa?

SH: Porque ela distrai e não enlouquece, e não destrói a minha cabeça com as loucura... com as qualquer coisa.

A primeira percepção suscitada a partir da leitura das falas de Super-Homem é que elas desvelam o sofrimento infantil. Não haveria sentido considerar a brincadeira como psicoterapêutica se, antes de 
tudo, não reconhecêssemos que há um conteúdo a ser terapeutizado. Nesse sentido, a Ludoterapia segue uma ética de cuidado no agora, no instante em que a dor é sentida pelo sujeito, ou seja, no momento em que como refere Super-Homem "a loucura está destruindo os pensamentos".

A função mediadora do brinquedo é o que justifica a prática da Ludoterapia, sendo toda a literatura embasada neste pressuposto. Por meio da brincadeira a criança expressa seus sentimentos, organiza pensamentos, inicia e resolve conflitos análogos aos da realidade, sente-se mobilizada (Axline, 1972; Affonso, 2012; Feijoo, 1997; Oaklander, 1980). Para este trabalho, destacamos o fato de serem as próprias crianças em atendimento ludoterapêutico falando sobre a função mediadora do brinquedo. Contudo, é preciso considerar que a função terapêutica não está dissociada da diversão que a brincadeira proporciona. Na psicoterapia pela fala, geralmente feita com adultos, o que se tem é o enfrentamento da questão de forma mais direta, verbalizada; diferente da Ludoterapia, que agrupa o enfrentamento da demanda com a ludicidade do brinquedo.

Dando continuidade, o diálogo aparece nas falas das crianças como outro recurso possível no exercício da psicologia clínica. Para as crianças, ele não se apresenta como uma simples conversa; antes, a escuta e a fala vêm carregadas de significados, tais como compartilhar assuntos íntimos (segredos), promover bem-estar, aprender algo.

I: Se você gosta de sorrir, venha pro psicólogo aquiii. [pausa]. Se você gosta de sorrir venha pro psicólogo que aqui você riiiiiii. [pausa].. Tan-Tan! [onomatopeia para comunicação de aeroporto]. Atenção senhores passageiros, a chamada para o psicólogo está em atendimento.

P: O psicólogo faz você sorrir?

I: E pra sorrir e pra perguntar algumas coisas também. É pra perguntar se você tá crescendo bem...Elas [psicólogas] podem perguntar "Como é que a fábrica exige muita coisa?" [referindo-se ao fato da mãe trabalhar muito] $P$ : Então quer dizer que o psicólogo faz perguntas?

L: É para saber sobre ela; porque quando a pessoa brinca, a pessoa aprende.

O que se destaca nos trechos das falas das crianças é que a escuta e a fala são explicadas através de um critério fundamental no que diz respeito à psicoterapia: o diálogo tem finalidade. Seja para crescer bem, para aprender ou para compartilhar assuntos privados, a escolha de falar sobre algo está acompanhada da consciência de que o psicólogo vai escutar o que foi dito, com atenção. Assim, a percepção da finalidade do diálogo diferencia as intervenções do processo ludoterapêutico das simples conversas; bem como ajuda cada criança a se implicar no seu processo ludoterapêutico.

Na literatura, a temática do diálogo está relacionada a, pelo menos, quatro princípios dispostos por Axline (1947/1972): o Princípio três, que versa sobre a permissividade para a criança expressar seus sentimentos; o Princípio quatro, que aponta para a importância de o terapeuta identificar os sentimentos expressos pela criança, e refleti-los; o Princípio cinco, que fala da necessidade de o terapeuta respeitar a capacidade da criança de resolver seus problemas, bem como de propiciar oportunidades para isso; e o Princípio seis, que afirma que a criança deve dirigir os diálogos. A partir disso, entende-se que os psicólogos reservam um lugar especial para a fala da criança, tomando-a como parte do processo terapêutico, e que a criança compreende tal posicionamento. Logo, podemos pensar que o conteúdo narrado não é aleatório.

\section{As Características da Ludoterapia}

Alguns trechos das falas das crianças se referem às características do processo ludoterapêutico. São destacados: a relação criança-terapeuta, o sigilo, a permissividade, a liberdade e o potencial de escolha. Além disso, surgem também narrativas que suscitam questionamentos a respeito da Consideração Positiva Incondicional, um dos pressupostos básicos, segundo a Abordagem Centrada na Pessoa, para o bom desenvolvimento do processo terapêutico.

B: O que o psicólogo faz? A gente conversa, a gente brinca, a gente pinta com eles se a gente quiser.

P: Conversa, brinca e pinta com eles se quiser... É isso?

B: Juntos!

P: Juntos.

B: A gente pinta junto.

Na literatura clássica, o trabalho do psicólogo orientado pela perspectiva fenomenológico-existencial está alicerçado na relação paciente-terapeuta. No que concerne à Ludoterapia essa relação se materializa mais nos atos do que no diálogo propriamente dito. Em outras palavras, com crianças a experiência de estar em terapia não se dá, majoritariamente, pelo o que o terapeuta fala ou o que fala com o terapeuta, antes, acontece na experiência da aceitação, da permissividade, da compreensão do sofrimento e na livre vivência de sentimentos. Nesse sentido, a relação paciente-terapeuta na Ludoterapia se diferencia dessa mesma relação no processo terapêutico adulto, visto que a vivência dela acontece mais nas ações do que nas palavras (Rogers, 1942/1987).

A relação paciente-terapeuta também aparece quando Barbie destaca o sigilo. A criança não sabe especificar os motivos pelos quais as informações da sessão são resguardadas, mas compreende que elas o são.

P: E a pessoa vai para o psicólogo para fazer o que?

B: Pra conversar sobre os segredos...

P: Aaaah! Pra conversar os segredos... E o psicólogo faz o que com eles? 
B: Não conta... Só fica entre eles dois. P: Porque ele não pode contar?

B: Porque... Não sei... Todo segredo que a criança conta pro psicólogo, ou alguém, ele não pode contar...

O compromisso com o sigilo é uma das informações que são dadas na primeira sessão (ou nas primeiras) com a criança. Embora seja algo novo no universo infantil, o compromisso do sigilo é condição para um bom trabalho. Não tornar público o conteúdo da sessão ajuda a criança a confiar no psicólogo e estimula a formação do vínculo terapêutico. Em relação aos pais/responsáveis, recomenda-se que o psicólogo explique à criança, em uma linguagem acessível, que haverá entrevistas com os mesmos, nas quais estes ouvirão do profissional as percepções que ele tem tido sobre o caso (Fernandes, 2010; Maichin, 2004), e que as informações compartilhadas serão aquelas necessárias à promoção do cuidado a ela e à garantia dos seus direitos. Dessa forma, quando as crianças participantes do processo ludoterapêutico falam espontaneamente da relação criança-terapeuta, estamos diante, para além da mera constatação de características, de um indicativo de que a qualidade desta também é percebida por elas. Sabendo desse reconhecimento e valorização,é possível reafirmar a necessidade dos psicólogos investirem na relação terapêutica, dispondo tempo para "tecer a intimidade" com o paciente (Cancello, 2008), respeitando o ser que se apresenta naquele instante.

Dando continuidade às características relatadas, destacou-se nas falas a liberdade para escolher os brinquedos desejados, bem como a autonomia de cada criança dentro do setting terapêutico. Neste sentido, elas apresentam o psicólogo como o profissional que vai acompanhá-las na atividade que optarão fazer.

\section{P: Como é que ele fica lá dentro? \\ D: Brincando. \\ P: Quem escolhe a brincadeira?}

D: É a pessoa. Coisa de carrinho, brincar de carrinho. (...)Se eu peço pra contar história ele conta... Ela conta.

Sobre isso, há divergências no que se refere à realização de ações diretivas ou não diretivas na Ludoterapia entre as atuações dos psicólogos infantis de base humanista e os de base gestáltica. Enquanto na primeira a criança dita o ritmo e as brincadeiras, na segunda o terapeuta pode, eventualmente, sugerir alguma atividade. Porém, em ambos os casos, o desejo da criança é respeitado.

Ora, se no processo ludoterapêutico o brinquedo é tomado como mediador de expressão, entende-se que ao escolher o que quer brincar a criança estará escolhendo o que quer expressar. É a consciência deste poder de decisão que também dá autonomia à criança. Sem ele, ou sem a consciência dele, o processo terapêutico estaria prejudicado (Vasconcelos \& Cavalcanti Júnior, 2008). A autonomia revela à criança um pressuposto básico do processo terapêutico: a hora lúdica pertence a ela, e não aos seus pais ou psicólogo.

Próximo à temática da liberdade de escolha está a da permissividade. Por permissividade entende-se a elaboração de um ambiente terapêutico que proporcione à criança a oportunidade de expressar os sentimentos que quiser. Em muitos casos essa permissividade está associada à escolha de brincadeiras que, comumente, a criança não realiza em seu cotidiano, seja por não ter condições de comprar o brinquedo ou porque a brincadeira não é aceita socialmente (por exemplo, quando a criança está com raiva dos pais e decide brincar de machucá-los). A permissividade está relacionada com o conceito da Liberdade Experiencial, que é a oportunidade dada à criança de elaborar as experiências e sentimentos como bem as entender (Rogers \&Kinget, 1977). Sobre isso, Super-Homem afirma:

SH: Aqui pode brincar de quaaalquer coisa. (...) E tem brincadeira que eu nunca brinquei no mundo.

P: Por que faz o que quiser?

SH: Porque... Pra distrair a cabeça da criança. SH: Pode bagunçar... Pode bagunçar tudo! P: Pode bagunçar?

SH: Tuudo!

$P:$ E é? E ela deixa assim? Ela não briga? SH: Deixa! Briga não.

A permissividade está relacionada a dois princípios da Ludoterapia propostos por Axline (1947/1972). O Princípio três fala da sensação de permissividade que o terapeuta deve estabelecer para que a criança se sinta livre para expressar seus sentimentos, pois a livre expressão dos sentimentos é o elemento que produz mudança no comportamento e promove a (re)significação dos eventos traumáticos. Entretanto, tal permissividade deve ser vivenciada respeitando-se os limites mínimos necessários para que a criança seja consciente da sua responsabilidade nas relações com o outro (por exemplo, não pode machucar o psicólogo) e para que ela não perca o contato com a sua realidade (por exemplo, não pode se machucar deliberadamente). Este é o oitavo princípio.

Aqui, novamente, vemos que as crianças reconhecem a importância de uma característica que, até então, era evidenciada apenas por autores e profissionais da psicologia. Se por um lado a permissividade apresenta-se, em muitos casos, como um recurso que causa espanto aos pais/responsáveis (imagine quão confuso pode ser para os pais a criança brincar de ser ladrão), por outro, ela é que facilita a expressão. Compreendendo os sentimentos expressos é possível ajudar a criança. A permissividade que é oferecida no setting terapêutico, ao contrário do espanto que causa aos que não participam do processo, apresenta-se como um importante recurso, reconhecido pelas crianças, no desenvolvimento da Ludoterapia.

Os dados também evidenciam a compreensão das crianças relativas ao segundo princípio, "O terapeuta aceita a criança exatamente como ela é" (Axli- 
ne, 1947/1972, p. 67). Quando abordado pela literatura, tal princípio remete à Consideração Positiva Incondicional, termo característico da Abordagem Centrada na Pessoa, que nomeia a atitude do psicólogo de acolher qualquer sentimento, pensamento ou informação que forem trazidos durante a sessão, sem oferecer julgamento ou resistência. Há ainda outras referências a tal atitude na literatura, sem, no entanto, fazer uso da nomenclatura de Rogers. Feijoo (2011) afirma sobre a necessidade de construir um espaço sem que haja a preocupação de garantir uma tutela adulta, viabilizando a potencialidade da criança de se revelar através do contato consigo.

As psicoterapias infantis de base fenomenológico-existencial consideram que esta aceitação da singularidade de cada criança deve ser percebida por cada paciente que inicia um processo terapêutico e, consequentemente, torna-se condição fundamental para que a criança manifeste livremente seus sentimentos. Entretanto, os participantes desta pesquisa demonstraram que, ao mesmo tempo em que se sentem livres para escolher as brincadeiras e agir conforme desejam dentro do setting terapêutico, também têm uma preocupação em agradar o psicólogo ou percebem nele uma vontade de agradá-los.

L: Ela tá assim, se olhando no espelho pra ir bem bonita. Imagine se ela fosse de cabelo assanhado...

P: $O$ que aconteceria?

L: Todo mundo ia ficar olhando pra ela fazendo "Aaaah" [faz uma cara assustada]. Você, $L$. [a recepcionista], tia E. [psicóloga], não vai querer brincar com ela.

É possível levantar alguns questionamentos em relação à Consideração Positiva Incondicional, proposta por Rogers. Seria ela percebida pela criança na mesma intensidade com que o terapeuta acredita oferecê-la? Ou ainda é possível não haver plena expressão dos sentimentos e pensamentos, mesmo quando a criança se sente aceita incondicionalmente? Sobre isso, Rogers (1999), refletindo sobre as atitudes terapêuticas, dentre elas a Consideração Positiva Incondicional, afirma:

nem sempre sou capaz de alcançar esse tipo de relacionamento com o outro, e algumas vezes, mesmo quando sinto tê-lo alcançado em mim mesmo, a outra pessoa pode estar demasiado assustada para perceber o que lhe está sendo oferecido (p. 39).

Assim é possível que, mesmo havendo aceitação por parte dos psicólogos, as crianças não estejam plenamente conscientes do que lhe está sendo ofertado. Considerando o lugar social que elas ocupam em nossa sociedade, com alto grau de exigências no cotidiano, não é comum que encontrem espaços em que não seja preciso agradar alguém para serem aceitas, o que poderia dificultar a vivência de ser aceito incondicionalmente.

A compreensão da relevância da aceitação da singularidade de cada criança pode ser ampliada a partir da fenomenologia existencial. Rogers (1999) reconhece na relação terapêutica, característica da relação Eu-Tu proposta por Buber (Buber, 2004). Numa concepção heideggeriana, trata-se de aceitar a alteridade do outro, o seu ser-mais-próprio, numa relação de cuidado referida por Heidegger como antepositivo (Heidegger, 1927/2005) que possibilita o vir-a-ser.

\section{A Apreciação da Ludoterapia}

Esta última unidade de significado diz sobre como as crianças avaliam a Ludoterapia, abordando os pontos positivos e os negativos destacados por elas. De uma forma geral, os sujeitos relataram que gostam do processo ludoterapêutico, recomendando-o, inclusive, às outras crianças. Os pontos negativos destacados se referem ao horário dos atendimentos e ao material da sala.

L: É tudo de bom para a criança!!! Vocês vão adorar, porque quando a pessoa vai, ela brinca, como eu. Quando eu era criança [a gente vai fingir queeu já sou adulta], eu ia pro psicólogo, que era tia E! Me divertia muuuito. Às vezes eu não gostava, mas eu era feliz. Vocês têm que ir. É tudo de bom!!!

É importante que a criança perceba a atividade como algo prazeroso, e não como um fardo, ou uma obrigação, ou ainda um "agrado aos pais". Ao gostarem de participar da hora lúdica, suas atitudes no setting podem ser mais autênticas, mais congruentes e, consequentemente, mais propiciadoras de mudanças. Além disso, a opinião das crianças reafirma o que vem sendo construído desde as obras das pioneiras em Ludoterapia, Axline (1972/1947) e Oaklander (1980), no que diz respeito à satisfação dos pacientes em participar do processo.

Em contrapartida, os participantes destacaram alguns elementos que merecem atenção dos psicólogos no exercício da profissão.

\section{D: Eu acho bom, eu só não gosto de acordar cedo.}

L: Assim, eu adoro tia E. [psicóloga], mas queria mais brinquedo novo (...). Eu gosto de treze brinquedos, de desenhar, gosto mais ou menos de conversar, eu gosto mais de brincar. Quando a gente conversa muito, a maioria não.

Em relação aos brinquedos, a literatura traz sugestões de material para a sala, bem como recomenda a substituição em caso de danificações; entretanto, não há apontamentos referentes à compra de brinquedos novos, bem como sobre a possibilidade da criança "enjoar" do material disponível (principalmente aquelas que estão há muito tempo em terapia). Não há na literatura a recomendação de substituição de brinquedos conservados, considerando apenas o tempo de uso na sala. Neste estudo, porém, tal situação foi citada, o que suscita alguns questionamentos. Podemos pensar que, para 
algumas crianças, o desinteresse pelos brinquedos da sala poderia significar que estes passaram a representar simples objetos, não investidos de simbolismo. Para outras, a falta de flexibilidade/criatividade viria a exigir uma grande diversidade de mediadores para a expressão simbólica. Os significados somente poderão ser compreendidos a partir da vivência de cada criança.

Sobre os horários, sabemos que são definidos pela disponibilidade da criança, de seus responsáveis e da agenda do psicoterapeuta; o que, muitas vezes, é quase um desafio. Entretanto destaca-se, através destas falas, que o horário das sessões pode ser um fator desestimulante no engajamento no processo terapêutico. Respeitando os limites de cada situação, a criança deve sempre ser questionada sobre a adequação do horário escolhido e as dificuldades/benefícios que ele oferece.

\section{Considerações Finais}

Neste estudo buscou-se narrativas infantis sobre a Ludoterapia. Seu principal objetivo foi transformar as compreensões das crianças em uma resposta mais ampla, sistematizada, inserida naquilo que se entende ser a produção do conhecimento científico dentro do referencial qualitativo. Nos resultados ficou evidente a necessidade dos psicólogos clínicos conquistarem mais espaços de atuação em lugares que oferecem algum tipo de serviço para as crianças (além do consultório), bem como a de elaborarem novas formas de intervenção, na tentativa de acolher o sofrimento delas e desassociarem a imagem às práticas elitistas. Além disso, caberia pensar em como facilitar o acesso às informações sobre a Ludoterapia para as crianças. Parece viável estabelecer diálogos que esclareçam à população infantil, bem como aos pais/responsáveis e à população em geral, que a Ludoterapia se apresenta como um instrumento de apoio em momentos de conflito e que visa ajudar à família como um todo, e à criança de uma forma mais específica, a encontrar estratégias que transformem o sofrimento em crescimento.

Em relação ao sofrimento, destaca-se o fato de algumas crianças significarem seus sentimentos como problema. Seduzidos por um ideal de criança que não se sustenta na realidade, sentimentos como medo, tristeza, raiva, ao serem sentidos, indicam parecer sugerir para elas que possuem uma "deficiência". Neste sentido, a sobrecarga de exigências em relação ao próprio eu faz surgir um contingente de crianças que se percebem como a personificação do problema. Um cenário que pede explicitamente a intervenção dos psicólogos em relação ao cuidado proporcionado no processo terapêutico.

Penso também ser importante refletir sobre a contribuição do psicólogo na consolidação dessas falas de sofrimento. Como o psicólogo tem respondido às expectativas que os pais/responsáveis geram em relação aos seus filhos? Ou, ainda, como o profissional, a partir do seu lugar de fala no cenário social, tem contribuído para cristalizar noções naturalizantes a respeito da infância ou do ser criança? O discurso infantil evidencia que existe demanda para agência política dos profissionais, que podem problematizar tanto a naturalização dos comportamentos infantis idealizados, quanto a reprodução dessas naturalizações.

Relacionando os resultados da pesquisa aos objetivos elementares da psicoterapia infantil, aponta-se que ao entrarem no processo psicoterapêutico as crianças compreendem os elementos constitutivos dele e que os recursos usados pelo mesmo têm uma finalidade;o psicólogo é visto como o profissional que vai contribuir com o desenvolvimento de formas de enfrentamento ao sofrimento; as crianças gostam de ir às sessões, que se percebem protagonistas da hora lúdica e que recomendam a experiência para as demais, ressaltando a diversão do ambiente lúdico. Entretanto, os participantes levantaram questões em relação aos horários de atendimento e à habituação com os brinquedos da sala, temas esses que podem ser melhor discutidos pela literatura.

Por fim, considerando que estamos na era da atenção especializada à infância, ressalta-se que um é tempo oportuno para que se alinhe a produção do conhecimento científico à polifonia das vozes infantis, resultando em mais pesquisas sobre psicoterapia clínica infantil.

\section{Referências}

Abrão, J. L. F. (2009). As origens da psicanálise de criança no Brasil: entre a educação e a medicina. Psicologia em Estudo (Maringá),14(3), 423-432.

Affonso, R.M.L. (2012) Ludodiagnóstico: investigação clínica através do brinquedo. Porto Alegre: Artmed.

Aguiar, L. (2014). Gestalt-terapia com crianças: teoria e prática. São Paulo: Summus Editorial.

Amorim, F.B.T., Andrade, A. B. \& Castelo Branco, P.C. (2015). Plantão psicológico como estratégia de clínica ampliada na atenção básica em saúde. Contextos Clínicos, 8(2):141-152.

Andrade, C.C. \& Holanda, A. F. (2010). Apontamentos sobre pesquisa qualitativa e pesquisa empírico-fenomenológica.Estud. Psicol. (Campinas), 27 (2), 259-268.

Aveline, M., Strauss, B. \& Stiles, W. B. (2007). Pesquisa em psicoterapia. In G. Gabbard, J. Beck \& J. Holmes (Orgs.), Compêndio de Psicoterapia de Oxford (pp. 606-623), Porto Alegre: Artmed.

Axline, V. M. (1972). Ludoterapia: a dinâmica interior da criança. Belo Horizonte: Interlivros. (Texto original publicado em 1947).

Barreto, C. L. B. T., Morato, H. T. P., Caldas, M. T. (2013). Prática psicológica na perspectiva fenomenológica. Curitiba, Juruá.

Buber, M. (2004). Eu e Tu. (8ª ed.). São Paulo: Centauro.

Cancello, L. A. G. (2008). O fio das palavras: um estudo de psicoterapia existencial. ( $5^{\mathrm{a}}$ ed.). São Paulo: Summus.

Ceitlin, L. H. F., Manfro, G. G., Jung, S. I. \& Cordioli, A. V. (2008). Pesquisa em psicoterapia. In A. V. Cordioli (Org.), Psicoterapias: abordagens atuais (pp. 830850), Porto Alegre: Artmed.

Cognet, G. (2013). Compreender e interpretar desenhos infantis. Petrópolis, Rio de Janeiro: Vozes. 
Costa, J. F. (1989). Ordem médica e norma familiar. $3^{\mathrm{a}}$ ed. Rio de Janeiro: Editora Graal.

Cruz, S. H. V. (Org.). (2008). A criança fala: a escuta de crianças em pesquisas. São Paulo: Cortez.

Dorfman, E. (1987). Ludoterapia. In C. R. Rogers (Org.), Terapia Centrada no Cliente (pp. 269-317), São Paulo: Martins Fontes. (Texto original publicado em 1951)

Feijó, L.P. \& Oliveira, D.S. (2016). Privações afetivas e relações de vínculo: psicoterapia de uma criança institucionalizada. Contextos Clínicos, 9(1):72-85.

Feijoo, A. M. C. (1997). Aspectos teórico-práticos na Ludoterapia. Acesso em 03 de outubro, 2009, de http:// www.ifen.com.br/revistas/ludoterapia/artigo_1. html

Feijoo, A. M. C. (2004). Temas em psicoterapia infantil. In V. A. Angerami-Camon (Org.), O atendimento infantil na ótica fenomenológico-existencial (pp. 51-74), São Paulo: Pioneira Thomson Learning.

Feijoo, A. M. C. (2011). A clínica psicológica infantil em uma perspectiva existencial. Revista da Abordagem Gestáltica - XVII(2): 185-192.

Fernandes, M. B. (2010). A família como parceira no atendimento gestáltico infantil. In S. Antony (Org.), $A$ clínica gestáltica com crianças: caminhos de crescimento (pp.177-201). São Paulo: Summus.

Forteski, R., Broges, C. D. Babiani, B. M., Sevegnani, G. R. (2014). Três abordagens em psicoterapia infantil. Revista Cesumar Ciências Humanas e Sociais Aplicadas, 19(2),p. 525-544.

Giorgi, A. (1985). Phenomenology and psychologica research. Pittsburgh: Duquesue University Press.

Giorgi, A. (1997). Phenomenological method as a qualitative research procedure. Journal of Phenomenological Psychology, 2(28), 235-260.

Gondra, J. G. (2000). A sementeira do porvir: higiene e infância no século XIX. Educação e Pesquisa, 26(1), 99-117.

Guarido, R. (2007). A medicalização do sofrimento psíquico: considerações sobre o discurso psiquiátrico e seus efeitos na educação. Educação e Pesquisa, 33(1), 151-161.

Heidegger, M. (2005). Ser e Tempo. $4^{\mathrm{a}}$ ed. Petrópolis: Vozes. (Texto original publicado em 1927)

Maichin, V. (2004). Os diversos caminhos em psicoterapia infantil. In V. A. Angerami-Camon (Org.), $O$ atendimento infantil na ótica fenomenológico-existencial (pp. 1-50), São Paulo: Pioneira.

Melo, S. M. V. \& Caldas, M. T. (2013) Merleau-Ponty e Gadamer: possibilidade de se pesquisar a prática de psicólogos clínicos. In C.L.B.T. Barreto, H.T.P. Morato \& M.T. Caldas. Prática Psicológica na perspectiva fenomenológica. (pp. 183-201).Curitiba: Juruá.
Müller, F. \& Carvalho, A. M. A. (2009). Teoria e prática na pesquisa com crianças: diálogos com William Corsaro. São Paulo: Cortez.

Oaklander, V. (1980). Descobrindo crianças: a abordagem gestáltica com crianças e adolescentes. São Paulo: Summus.

Parise, C. L., Accioly, M.C. \&Garrafa, T. C. (2011). Acompanhamento terapêutico: invenções terapêuticas no espaço público. In M. Wajntal. Clínica com crianças: enlaces e desenlaces, (pp 119-129). São Paulo: Casa do Psicólogo.

Paulon, S. (2004). Clínica Ampliada: que(m) demanda ampliações? In T. G. Fonseca \& S. Engelman (Orgs.), Corpo, arte e clínica (pp. 259-274), Porto Alegre: Ed. UFRGS.

Philippi, M. M. (2010). Da intenção à ação: Gestalt-Terapia, ética e prática profissional com crianças e adolescentes. In S. Antony (Org.), A clínica gestáltica com crianças: caminhos de crescimento (pp.17-46),São Paulo: Summus.

Protásio, M. M. (1997). Técnicas de Gestalt-terapia aplicadas à ludoterapia. Acesso em 03 de outubro, 2009, de http://www.ifen.com.br/revistas/ludoterapia/artigo 2.html.

Rogers, C. R. (1987).Terapia Centrada no Cliente. São Paulo: Martins Fontes. (Texto original publicado em 1942)

Rogers, C. R. (1999). Tornar-se pessoa. São Paulo: Martins Fontes.

Rogers, C. \& Kinget, G. (1977). Psicoterapia e relações humanas. (2 ${ }^{\mathbf{a}}$ ed.). v.1. Belo Horizonte: Interlivros.

Sousa, D. (2006). Investigações em psicoterapia: contexto, questões e controvérsias - possíveis contributos da perspectiva fenomenológico-existencial. Análise Psicológica, 24(3), 373-382.

Vasconcelos, T. P. \& Cavalcanti Júnior, F. S. (2008). Concede-se morte, suscita-se vida - Um golpe formativo em um grupo de ludoterapia. In F. S. Cavalcanti Jr. \& A.F. de Sousa (Orgs.), Humanismo de funcionamento pleno: tendência formativa na abordagem centrada na pessoa (pp. 145-155), São Paulo: Alínea.

Vitola, J. O. C., Minella, F. \& Silveira, G. M. (2009). A trajetória de Pequenino - o processo de uma psicoterapia infantil sob o enfoque humanista-existencial. In M. M. K. Macedo (Org.), Fazer psicologia: uma experiência em clínica-escola (pp. 123-140), São Paulo: Casa do Psicólogo. 
Munique Therense Costa de Morais Pontes é Psicóloga, Especialista em Psicologia Clínica Fenomenológico-Existencial e Mestre em Psicologia pela Universidade Federal do Rio Grande do Norte (UFRN); Doutoranda em Saúde Coletiva pelo Instituto de Medicina Social (IMS) da Universidade do Estado do Rio de Janeiro (UERJ) e Professora da Escola Superior de Ciências da Saúde da Universidade do Estado do Amazonas (UEA). Endereço Institucional:Universidade do Estado do Amazonas. Rua Gabriel Gonçalves, 9, Aleixo, Manaus/AM. CEP 69060010. mtherense@gmail.com

Recebido em 30.10.16

Primeira decisão editorial em 14.10.17

Segunda decisão editorial em 18.02.18

Aceito em 15.03.18 